\title{
Coping with Work Stressors and Paving the Way for Flow: Challenge and Hindrance Demands, Humor, and Cynicism
}

\author{
Lise A. van Oortmerssen ${ }^{1}$ (D) Marjolein C. J. Caniëls ${ }^{1}$ (D) $\cdot$ Marcel F. van Assen $^{2}$
}

Published online: 23 September 2019

(c) The Author(s) 2019

\begin{abstract}
Although the concept of flow at work is increasingly receiving scholarly attention, knowledge about the interaction between challenge and hindrance stress demands in the context of flow is still lacking. Moreover, little is known about the stress-relieving capacity of coping mechanisms in connection to work-related flow. The aim of our study is to investigate whether and how challenge stress demands are related to work-related flow, and whether this relationship is moderated by a three-way interaction between challenge stress demands $\times$ hindrance stress demands $\times$ use of humor/cynicism. For this study we use survey data from 265 employees of a financial service organization in the Netherlands. Results clearly indicate a positive linear association between challenge demands and workrelated flow and a negative association between hindrance demands and flow. Support is found for an interaction effect between challenge and hindrance stress demands, showing that hindrance demands weaken the positive association between challenge demands and work-related flow. Finally, cynicism is found to alter this relationship between work stress demands and work-related flow, increasing the negative effect of hindrance demands and confirming the expected three-way interaction. Results from this study have implications for the theory on work-related flow and advance the challenge-hindrance stressors framework. Insights from this study suggest that managers who wish to foster work-related flow should be alert to the use of cynicism among employees and address organizational issues that cultivate the negative attitude underlying this.
\end{abstract}

Keywords Flow $\cdot$ Work demands $\cdot$ Humor $\cdot$ Cynicism

Lise A. van Oortmerssen

lise.vanoortmerssen@ou.nl

Marjolein C. J. Caniëls

marjolein.caniels@ou.nl

Marcel F. van Assen

m.vanassen@tias.edu

1 Faculty of Management, Science and Technology, Open University of the Netherlands, PO Box 2960, 6401 DL Heerlen, The Netherlands

2 TIAS, School for Business and Society, Tilburg University, Warandelaan 2, PO Box 90153, 5000 LE Tilburg, The Netherlands 


\section{Introduction}

Organizations benefit from employees who experience flow at work. When workers are 'in the zone', they are absorbed in an activity that they are motivated to conduct without considering potential rewards for it. During a flow experience, workers are challenged to use their full potential and they find great pleasure in the activity. Flow provides a fulfilling, energizing experience: an optimal experience. Employees finding flow at work are happier, are more motivated and perform better (e.g. Demerouti 2006; Engeser and Rheinberg 2008).

Since the introduction of the concept of flow by Csikszentmihalyi $(1975,1990)$ in the 1970s, countless scholars have studied flow dynamics in a wide variety of contexts. These include leisure, education, elite sports, music, gaming and more (for an overview see Engeser and Schiepe-Tiska 2012). Flow theory has been refined over the years, and is still further developing. More recently, flow is also being studied in the context of work (Bakker 2008; Bakker and van Woerkom 2017). Various antecedents and effects of flow that are specific for an organizational setting have been addressed in the literature. Themes discussed and studied in relation to work-related flow are among others: job characteristics (Demerouti 2006), leadership (Lovelace et al. 2007; Sosik et al. 1999; Zubair and Kamal 2015), job resources (Fagerlind et al. 2013; Mäkikangas et al. 2010; Salanova et al. 2006), energy and daily recovery (Demerouti et al. 2012).

Although the concept of flow at work is increasingly receiving scholarly attention, the impact of work stressors, a far-reaching theme in the field of management and organization, on flow has not yet been addressed. Previous research has shown that work stress demands affect the performance and well-being of employees (see e.g. Cavanaugh et al. 2000; LePine et al. 2016; Podsakoff et al. 2007; Ventura et al. 2015). Generally, two opposing types of work stress demands are distinguished, namely challenge and hindrance demands (Folkman et al. 1986). Challenge demands are positively valued demands, for example complex responsibilities. They allow for growth (Bricteux et al. 2017; Ventura et al. 2015). Hindrance demands, by contrast, are difficulties that are considered to be potentially harmful for performing one's work (Ventura et al. 2015). Examples are lack of control and lack of social support. Challenge demands are found to have positive associations with work outcomes, whereas hindrance demands are negatively associated with work outcomes (see e.g. Cavanaugh et al. 2000; LePine et al. 2016; Podsakoff et al. 2007; Ventura et al. 2015).

In flow theory, the balance between challenge and skills plays a key role. In this challenge-skill balance, challenge refers to an individual's perception of a specific activity that is being conducted by the individual. Although studies have indicated that the relationship between challenge-skill balance and flow experience may be moderated by situational factors (Bricteux et al. 2017; Engeser and Rheinberg 2008; Fong et al. 2015), generally it is understood that matching levels of challenge and skill, and especially moderate to high challenge in combination with moderate to high skill, is conducive to flow (e.g. Fullagar et al. 2013; Nakamura and Csikszentmihalyi 2002). Challenges form an opportunity to use one's full potential and thereby open up the possibility for an optimal experience, and hence flow. Likewise, it could be argued, when an activity is being conducted in a context involving work challenges, this may encourage employees in a similar way, fostering a flow experience. However, in the presence of hindrance demands, this effect may be dampened.

Knowledge about the interaction between challenge and hindrance stressors in the context of flow is still lacking. Moreover, there is a call for more research into the effects on work-related flow of person-related factors, as opposed to situation-related factors (Bakker 
and van Woerkom 2017). It may be so that certain personal strategies can relieve the negative effect of hindrance stressors and enhance the positive effects of challenge stressors. Recent studies in the field of humor and cynicism have shown a connection of the use of humor and the use of cynicism with individual work outcomes (see e.g. Chiaburu et al. 2013; Mesmer-Magnus et al. 2012). Yet, little is known on the effects of the use of humor and the use of cynicism in connection to work-related flow.

The aim of our study is to investigate the interaction between challenge and hindrance demands in relation to flow. Moreover, we examine the use of humor and cynicism and their potential relieving and aggravating effects towards work stressors and flow. In this study we use survey data from 265 employees of a financial service organization in the Netherlands to analyze whether and how challenge demands are related to work-related flow, and whether this relationship is moderated by a three-way interaction between challenge demands $\times$ hindrance demands $\times$ use of humor/cynicism.

The present study advances prior research in several ways. First, studies that specifically address antecedents of flow at work are still scarce. Our study advances flow theory with regard to flow antecedents and prohibitors in organizational contexts. Second, although several studies have addressed how work stress demands affect work outcomes (see e.g. Cavanaugh et al. 2000; LePine et al. 2016; Podsakoff et al. 2007; Ventura et al. 2015), these studies mostly focus on isolated relationships between work stress demands and outcomes (e.g. LePine et al. 2016). The present study investigates the interaction of challenge demands with hindrance demands. This research design allows for analyzing how different work stress demands have a combined influence on work-related flow. Moreover, our study explicitly connects work stress demands to work-related flow, which is a connection that has not been studied until now, yet is of high interest to organizations. Third, our study provides insights into the role of person-related factors with regard to the relationship between work stress demands and flow. More specifically, by investigating the moderating role of humor and cynicism in the work demands-flow relationship we increase the knowledge about the effects of these types of coping behavior in connection to work-related flow. In organizations, these insights may inform managers about opportunities for interventions that may help employees in finding flow at work.

\section{Theoretical Frame}

\subsection{Flow at Work}

Flow is a magic word. Flow is good and flow is fun-everyone likes to be in flow. Flow is a state of optimal experience (Csikszentmihalyi 1975, 1990). On top of that, flow often goes together with optimal performance (e.g. Aubé et al. 2014; Csikszentmihalyi 1990; Demerouti 2006; Engeser and Rheinberg 2008). An individual in flow is absorbed in an activity that is experienced as intrinsically rewarding, in a way that makes one lose all sense of time and of the self. Flow, or being 'in the zone', comprises a perfect synchronization of cognitive, affective and behavioral elements (Nakamura and Csikszentmihalyi 2002). In line with this view, we consider the flow experience as a complex dynamic that can evolve when multiple factors align. The most essential precondition for the development of a flow experience is that the individual, during an activity, perceives a balance between challenges and skills (Engeser and Rheinberg 2008; Moneta and Csikszentmihalyi 1996; Nakamura and Csikszentmihalyi 2002). According to Ceja 
and Navarro (2012, p. 1104), employees "cannot enjoy the same activity with the same intensity more than once" (see also Csikszentmihalyi 1990). People constantly learn and develop their skills. The challenge offered by a certain activity diminishes if the circumstances and the pursued performance level remain the same. Therefore, in order to create the necessary balance between (perceived) challenge and skills, and allow for a flow experience, activities must continuously be re-created.

Recently, flow is more and more studied in work contexts. Research has indicated that flow is experienced more often during work time than during leisure time (Csikszentmihalyi and LeFevre 1989). Apparently, the necessary conditions for flow are present more often during workdays than during non-workdays. As explained by Ceja and Navarro (2011), in order to experience flow, psychic energy must be structured and directed. Therefore, work characteristics that give structure are likely to foster flow. Moreover, as pointed out by Fullagar and Kelloway (2009), workplace activities that require complex skills are conducive to flow.

Work-related flow is often approached as a three-dimensional construct, encompassing intrinsic motivation, absorption, and enjoyment (e.g. Salanova et al. 2006; Bakker 2008, Ceja and Navarro 2011, Fagerlind et al. 2013). Some authors point at a relationship of the work-related flow concept with the much studied concept of work engagement, which refers to a positive and fulfilling work-related state of mind. Notably, the constructs of work engagement and work-related flow overlap in the sense that both include the dimension of absorption. An important difference between the concepts is in the time frame (Makikangas et al. 2010; Rodriguez-Sanchez et al. 2011; Schaufeli et al. 2002). Flow refers to a specific activity with a limited time frame, which gives rise to a short-lasting optimal experience, whereas engagement refers to a more general state of mind, a trait. Recently, work engagement is also studied as a state concept focusing on intra-individual differences between one day and the next (e.g. Breevaart et al. 2012). This seems to further diminish its differences with the flow concept. Still, the central ideas behind the concepts of work-related flow and state work engagement are essentially different. Flow is an optimal experience triggered by a specific activity, whereas state work engagement refers to an attitude towards one's job.

Flow has multiple benefits for employees and for organizations. Studies have shown that flow at work has associations with positive mood (Eisenberger et al. 2005; Fullager and Kelloway 2009), after-work energy (Demerouti et al. 2012), and well-being (Rivkin et al. 2018). A study by Demerouti (2006) indicated that flow fosters both in-role and extra-role performance for conscientious employees. In a study conducted by Aubé et al. (2014) flow was found to increase team performance. In the words of Salanova et al. (2006, p. 1), flow at work elicits "an upward spiral of personal and organizational resources". Hence, it is relevant to know what factors may enhance the chances for experiencing flow.

Factors that may enhance flow can be person-related and situation-related factors. With regard to person-related factors, research has shown the predictive roles of commitment (Rivkin et al. 2018); skill variety and utilization (Fagerlind et al. 2013; Fullagar and Kelloway 2009); and self-efficacy (Salanova et al. 2006). However, whether an unfolding flow experience turns into an optimal experience or is cut short depends not only on the person, but also on the organizational environment (Nakamura and Csikszentmihalyi 2002). With regard to organization-related factors, studies have suggested effects of motivating job characteristics (Demerouti 2006); organizational resources (Salanova et al. 2006); and level of autonomy at work (Fagerlind et al. 2013; Fullagar and Kelloway 2009). 


\subsection{Flow and Work Demands}

Employees are constantly challenged by all sorts of work demands. The effects of work demands may vary depending on how they are perceived-i.e. whether they are considered as challenges or as hindrances. Challenge demands are demands that are perceived in a positive way and allow for personal development (Boswell et al. 2004; Ventura et al. 2015). Challenge demands, such as time pressure or complex responsibilities, are found to have positive associations with job satisfaction (Cavanaugh et al. 2000; Podsakoff et al. 2007), organizational commitment (Podsakoff et al. 2007), and performance (e.g. LePine et al. 2016). In addition, challenge demands in the form of mental overload have been shown to positively affect engagement (Ventura et al. 2015). Since engagement and flow are closely related phenomena, it is likely that challenge demands also are positively associated with flow. This reasoning is in line with the transactional theory of stress (Lazarus and Folkman 1984), which suggests that stress may have positive implications for the individual when it is appraised as a challenge or opportunity. When work challenges are approached as opportunities for growth, and the required skills and resources to deal with them are available, flow is likely to be triggered.

Other effects of challenge demands that are identified in the literature include motivation (LePine et al. 2005) and positive emotions and well-being (Ventura et al. 2015; Widmer et al. 2012). Given that intrinsic motivation and enjoyment are dimensions of work-related flow, it seems again likely that challenge demands have a positive association with work-related flow. Also Bakker and van Woerkom (2017) argued and proposed that challenging job demands, in combination with job resources, are positively related to work-related flow. Moreover, challenges form a fundamental element in general flow theory as part of the much documented challenge-skill balance: especially challenges perceived as moderate to high (in combination with moderate to high skills) are considered to trigger flow experiences (Fullager et al. 2013; Nakamura and Csikszentmihalyi 2002). In line with this notion, and based on their study of work-related flow experiences, Ceja and Navarro (2012) concluded that perceived challenge plays a key role in flow changes over time. Based on these lines of reasoning, we hypothesize that:

H1 Challenge demands are positively associated with work-related flow

Work demands that are perceived in a negative way and conceived as being potentially harmful, for example because they are beyond one's control, are denoted as hindrance demands. In accordance with the transactional theory of stress (Lazarus and Folkman 1984), which suggests that stress may have negative implications for the individual when it is appraised as harmful, or threatening, studies have shown that hindrance demands, such as inadequate resources, role conflict, administrative hassles, or job insecurity, have opposite effects on work outcomes when compared to challenge demands (Boswell et al. 2004; LePine et al. 2016; Podsakoff et al. 2007; Ventura et al. 2015). Following these studies leads us to assume that hindrance demands are negatively associated with work-related flow. Moreover, since work hindrance demands have been found to be negatively related to engagement (Ventura et al. 2015), it seems likely that they also are negatively related to flow. When an employee feels threatened by demands that embody no inherent growth potential, negative emotions and decreased motivation may occur. Moreover, this situation constitutes a lack of the challenge-skill balance that is required for a flow experience. Therefore, we hypothesize that:

$\mathrm{H} 2$ Hindrance demands are negatively associated with work-related flow 
The literature about stress demands indicates that hindrance and challenge stressors have differential effects on several important employee outcomes (Cavanaugh et al. 2000; LePine et al. 2016), such as performance, motivation, and job attitudes (LePine et al. 2005; Podsakoff et al. 2007). Knowledge is still lacking about what happens with respect to the flow experience when challenge demands and hindrance demands are both present. This is a common situation in everyday organizational contexts. For example, an employee is challenged to use his or her skills in full effort in a demanding but meaningful work activity, however, at the same time he or she is hindered by unfavorable circumstances beyond his or her control. In such situations it seems less likely that a flow experience will unfold: the positive effect of perceived challenges on how work activities are experienced in terms of flow level may decrease due to perceived hindrance demands. In other words, we expect that hindrance demands interact with challenge demands and suppress the favorable effect of challenge demands on flow. Hence, we hypothesize that:

H3 Challenge and hindrance demands interact in the following way: Hindrance demands decrease the positive association between challenge demands and work-related flow

\subsection{Flow and Coping with Hindrance Demands}

Recently, Bakker and van Woerkom (2017) presented a self-determination model of flow. This model puts a focus on flow antecedents that employees can proactively influence, as opposed to situational flow antecedents which are externally determined. Departing from a self-determination theoretical perspective, they list three types of factors that, expectedly, influence basic need satisfaction and flow: organizational context factors; personal resources; and self-determination strategic factors. It is proposed that this last category of factors allows employees to steer towards flow experiences using four strategies: selfleadership; strengths use; job crafting; and playful work design. Self-leadership strategies include, for example, constructive thought patterns and self-goal setting, -reward, and -feedback. These strategies may inhibit disturbing beliefs and increase one's motivation. Strengths use strategies focus on personal traits or skills that allow an employee to be authentic and perform at one's best, such as creativity, empathy, and bravery. Job crafting strategies involve the active steering or changing of the job content and one's tasks. These strategies can increase the challenge-skill balance. Playful work design strategies are aimed at bringing amusement, entertainment and humor in one's work. By self-setting one's targets in fun and enjoyable ways, an employee may experience increased volition and autonomy. All these strategies are expected to have an impact on basic need satisfaction and flow. In line with Bakker and van Woerkom's notion that employees may employ strategies that have a favorable effect on flow experiences, we will discuss the use of humor as well as the use of cynicism as personal strategies that have potential impacts on the buffering effect of hindrance demands on the positive relation between challenge demands and flow.

Humor consists of amusing communications that may generate positive feelings and cognitions in employees, teams, and organizations (Romero and Cruthirds 2006). Different types of humor are assumed to serve different goals and have different consequences (Fritz et al. 2017; Romero and Cruthirds 2006). Two important dimensions of humor are: (1) the extent to which humor is enhancing the self, versus enhancing the relationships with others; and (2) the extent to which humor is benign versus harmful. Affiliative humor is aimed at social connection and enhances the ties among people, for example by telling jokes. Aggressive humor is aimed at enhancement of the self at the cost of others, for example 
by belittling someone. Self-enhancing humor focuses on the self in a benign way and may be employed as a means of keeping a cheerful perspective. Self-defeating humor involves ridiculing oneself. It may be utilized to reduce one's status in order to make oneself more approachable (Romero and Cruthirds 2006).

A stress-buffering effect of humor has been proven in multiple studies (e.g. Fritz et al. 2017; Kuiper and Martin 1993; Kuiper et al. 1995; Martin et al. 1993; Mesmer-Magnus et al. 2012). Individuals who score high on using humor are less affected by stressful events and situations than individuals who score low on the use of humor. In a study conducted by Fritz et al. (2017), the effects of different humor styles were compared: selfenhancing humor had the strongest relations with stress buffering outcomes. This effect of using humor can be understood in terms of a cognitive reappraisal of stressful events and situations (Fritz et al. 2017; Kuiper 2012; Martin et al. 1993). Using humor can be regarded as a cognitive strategy that helps individuals to alter their perspective on stressful circumstances. This is especially true when circumstances are appraised as a threat or a hindrance as opposed to a challenge. When one experiences adversity, i.e. a hindrance stressor, it has an emotional impact, which one may try to relieve by using a coping strategy that addresses this emotional aspect. In such situations, humor may provide a sense of dominance and control over a situation (Henman 2001; Romero and Cruthirds 2006). In addition, humor gives people a positive mood, which allows them to see multiple perspectives (Fritz et al. 2017; Romero 2005), specifically in situations where they feel constrained and hindered by circumstances. The reappraising of a stressful situation might enable individuals to perceive the situation in less threatening or harmful ways. When employees are successful in positively altering the perceived impact or relevance of hindrance stress demands - to some extent and for some time, this raises the chances for a pleasant absorption in a challenging work-related activity. In other words, we expect a three-way interaction, in which the use of humor buffers the negative effect of hindrance demands on the challenge demands-flow relationship. Hence, in line with this stress-buffering mechanism of humor, we hypothesize that:

$\mathrm{H} 4$ The use of humor decreases the weakening effect of hindrance demands on the challenge-flow relationship

Organizational cynicism is a negative attitude towards the actions, motives, or values of individuals in the organization, the organization's management, or the organization as a whole (Byrne and Hochwater 2008). Cynicism is a way of responding to adverse circumstances at work. It is a coping mechanism that employees may use to deal with, for example, disappointing actions taken by management (Naus et al. 2007; Reichers et al. 1997). A cynic attitude diminishes the relevance of the offending action (Blaser 1976; Byrne and Hochwater 2008). It is a silent form of resistance (Karfakis and Kokkindis 2011). Cynicism has multiple dimensions, comprising cognitive, affective, and behavioral components (Byrne and Hochwater 2008; Kim et al. 2009).

Many studies on cynicism have shown that cynicism has negative outcomes for organizations, for example, a lack of commitment, reduced performance, and turnover intentions (see Chiaburu et al. 2013, for a meta-analysis of consequences of organizational cynicism). There are some signals that certain types of cynicism in the workplace may also have beneficial outcomes. Kim et al. (2009) found that different dimensions of cynicism differently relate to work outcomes. In their multi-method study of top management credibility and employee cynicism, affective cynicism, consisting of emotional reactions such as irritation and aggravation, was negatively associated with self-assessed performance, however, behavioral cynicism, defined as negative, disparaging behavior, was positively associated with self-assessed performance. Brandes and Das (2006) argue that different kinds 


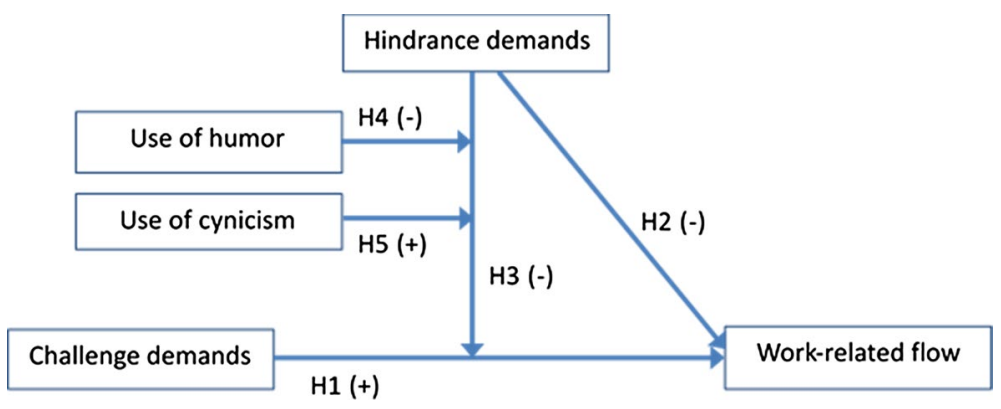

Fig. 1 Research model

of cynicism relate differently to the relationship between high stress and performance. Expressing cynical humor may help employees in keeping a free mind, thereby reducing the strength of the relationship between high stress and performance. By contrast, cynical criticism lacks the positive element included in cynical humor and may cause alienation of colleagues and a feeling of depression, thereby increasing the strength of the relationship between high stress and performance and making repeated cynical behavior an ineffective coping mechanism (Brandes and Das 2006).

Concluding from the above, cynicism in its multidimensional definition is generally considered to have adverse associations with work outcomes and to be an ineffective coping mechanism. In line with this, we expect that the use of cynicism as coping mechanism will have an adverse association with flow. Cynicism is likely to interact with work demands, by emphasizing the negative feelings caused by hindrance demands, in a way that increases their adverse effects on the challenge-flow relationship. We hypothesize that:

H5 The use of cynicism increases the weakening effect of hindrance demands on the challenge-flow relationship

All hypothesized relationships are displayed in Fig. 1.

\section{Method}

\subsection{Sample and Procedure}

We gathered survey data from 265 mid and back office employees of a Dutch financial service organization. Stressors may vary across organizations and departments, therefore we targeted employees from one business unit within this single organization. At the time of the data collection, employees had to cope with various stressors: productivity and innovation demands set by management were high, and there were rumours that part of the employees would potentially lose their jobs.

Prior to the distribution of the online questionnaire, two subject-matter experts and two professionals commented on the layout of the questionnaire and the clarity of survey items. Based on their suggestions, we slightly modified the design of the questionnaire to facilitate the readability of the items. We conducted a survey involving questions that were not invasive. In such cases, our research ethics committee requires us to apply informed consent. Therefore we adopted the following procedure. The cover letter of the survey described the relevance of the study and emphasized the anonymity of respondents. We 
explicated that there were no right or wrong answers and that we were purely interested in respondents' opinions. We provided contact information of the research team, so that questions about the questionnaire or in response to the questionnaire could be dealt with. Respondents could withdraw their participation at any time during the survey. By starting the questionnaire, respondents were explicitly providing their informed consent.

In total 385 employees received the questionnaire. After one week and again after two weeks reminders were sent. We received 278 (72.2\%) returned questionnaires. After deleting incomplete and/or inconsistent questionnaires, 265 remained (68.8\% response rate). The sample consists of 135 (50.9\%) male respondents, which reflects the overall gender distribution within the organization. The average age of the respondents is 42.3 years $(\mathrm{SD}=11.2)$ and the average tenure is 14.1 years $(\mathrm{SD}=11.2)$.

Self-reported measurements were used, which is not unusual in the management literature (Ng and Feldman 2012). Specifically for our variable of interest, work-related flow, self-reported measures seem warranted, because flow may be hard for others to assess. Nevertheless, we employed several procedural remedies to minimize the risk of bias (Podsakoff et al. 2012). We guaranteed respondents' anonymity and requested that they answered the questions as honestly as possible. In this way, we tried to minimize the risk of respondents' evaluation apprehension as well as social desirability bias (Podsakoff et al. 2003). Furthermore, our research model is quite complex as it contains three-way interactions. This implies that respondents cannot easily combine related items when answering the questionnaire, which may produce a common method variance biased pattern in the responses (Chang et al. 2010).

\subsection{Measures}

The survey used established, validated multi-item scales. The original English items were translated into Dutch, the local language of target respondents. We followed the back-translation procedure recommended by Brislin (1986). All scales were anchored by ' 1 ' (strongly disagree) to ' 5 ' (strongly agree), unless reported otherwise. We provided verbal labels for the scales and avoided using bipolar numerical scale values (e.g., -2 to +2 ) in order to reduce acquiescence bias (Kulas et al. 2008). The survey covered the following construct variables.

Work-related flow was measured with thirteen items from the WOrk-reLated Flow inventory (WOLF) from Bakker (2008), which includes the dimensions absorption, work enjoyment and intrinsic work motivation. We conducted a three-factor confirmatory factor analysis to examine the distinctiveness of the dimensions of flow. Residuals were not allowed to correlate. The analysis showed that the one-factor solution had a better fit $\left(\chi^{2}=155.431, \mathrm{df}=62, \chi^{2} / \mathrm{df}=2.51, \mathrm{CFI}=.949, \mathrm{RMSEA}=.076\right)$ than the three-factor solution $\left(\chi^{2}=209.103, \mathrm{df}=51, \chi^{2} / \mathrm{df}=4.10, \mathrm{CFI}=.913, \mathrm{RMSEA}=.108\right)$. Therefore, we did not distinguish separate dimensions in our scale. An example item of the WOrk-reLated Flow inventory is "I get carried away by my work". The reliability of the scale was $\alpha=.883$.

Work stress demands employees can appraise certain stressors as challenging or hindering (LePine et al. 2016). Conform LePine et al. (2016), we measured the extent to which employees appraise their work demands as challenging or hindering. The resulting variables are labelled for short "challenge demands" and "hindrance demands". Challenge demands were assessed through three items developed and validated by LePine et al. (2016). An example item is "I feel the demands of my job challenge me to achieve personal goals and accomplishment". The estimated reliability was $\alpha=.880$. Hindrance demands 
were also measured with three items developed by LePine et al. (2016). An example item is "In general, I feel that my job hinders my personal accomplishment". The estimated reliability was $\alpha=.811$. Confirmatory factor analysis confirmed a structure of two separate dimensions: challenge and hindrance $\left(\chi^{2}=21.692, \mathrm{df}=8, \chi^{2} / \mathrm{df}=2.71, \mathrm{CFI}=.984\right.$, RMSEA $=.081$ ).

Cynicism was assessed by adopting the six-item measure from Naus et al. (2007). An example item is "I use cynical humor to "let off steam"”. The estimated reliability was $\alpha=.714$. Confirmatory factor analysis confirmed a one-factor structure $\left(\chi^{2}=17.087, \mathrm{df}=9\right.$, $\mathrm{CFI}=.967, \chi^{2} / \mathrm{df}=1.90, \mathrm{RMSEA}=.058$ ).

Humor was measured with five items designed by Avolio et al. (1999). An example item is "I use amusing stories to defuse conflicts". The estimated reliability was $\alpha=.855$. Confirmatory factor analysis confirmed a one-factor structure $\left(\chi^{2}=28.373, \mathrm{df}=5, \mathrm{CFI}=.958\right.$, $\left.\chi^{2} / \mathrm{df}=5.68, \mathrm{RMSEA}=.133\right)$. Note that recommendations for the cut-off values for various fit measures have been lowered over the last fifteen years (Hooper et al. 2008). Whereas before an RSMEA of .13 was acceptable, currently it is considered a poor fit. As we cannot theoretically justify a modification of the humor measure, we have conducted our analyses with humor as one factor. Reassuringly, a CFI of above .95, as is the case in our data, is presently recognised as indicative for a good fit (Hooper et al. 2008; Hu and Bentler 1999).

We assessed several control variables. Gender was measured as a dichotomous variable coded as 0 for male and 1 for female. Age was measured in years. Tenure was measured by years of experience in the current job or a job with a comparable function. Furthermore, we had control variables for education level (in categories ranging from $1=$ low level applied education to $7=$ doctorate) and function level. Function level was included in the model in the form of two dummy variables, namely middle management and higher management.

\subsection{Analytical Strategy}

Prior to testing the hypothesized relationships, we mean-centered our measures to eliminate some of the effects of multicollinearity. We used linear multiple regression analysis to examine the hypothesized work stress demands-flow relationship. In addition, we investigated models with two-way interactions. Furthermore, we examined the hypothesized two three-way interaction effects of challenge demands, hindrance demands and (a) humor and (b) cynicism.

\section{Results}

Table 1 reports the means, standard deviations, reliability estimates, and correlations for all measures.

Table 1 indicates that except for function level, the control variables are not substantially associated with any of the main variables (i.e., having a correlation coefficient above .2). Following Becker's (2005) plea for parsimonious designs, we will only control for function level in the remainder of our analyses. With linear multiple regression analyses we regressed challenge stressors and hindrance stressors on work related flow, moderated by (a) humor and (b) cynicism. We analysed direct effects as well as interaction effects. The results are presented in Table 2 .

Model 1 (M1) assesses the relationship between challenge demands and hindrance demands with work-related flow ( $\mathrm{H} 1$ and $\mathrm{H} 2)$. As expected, challenge demands are 


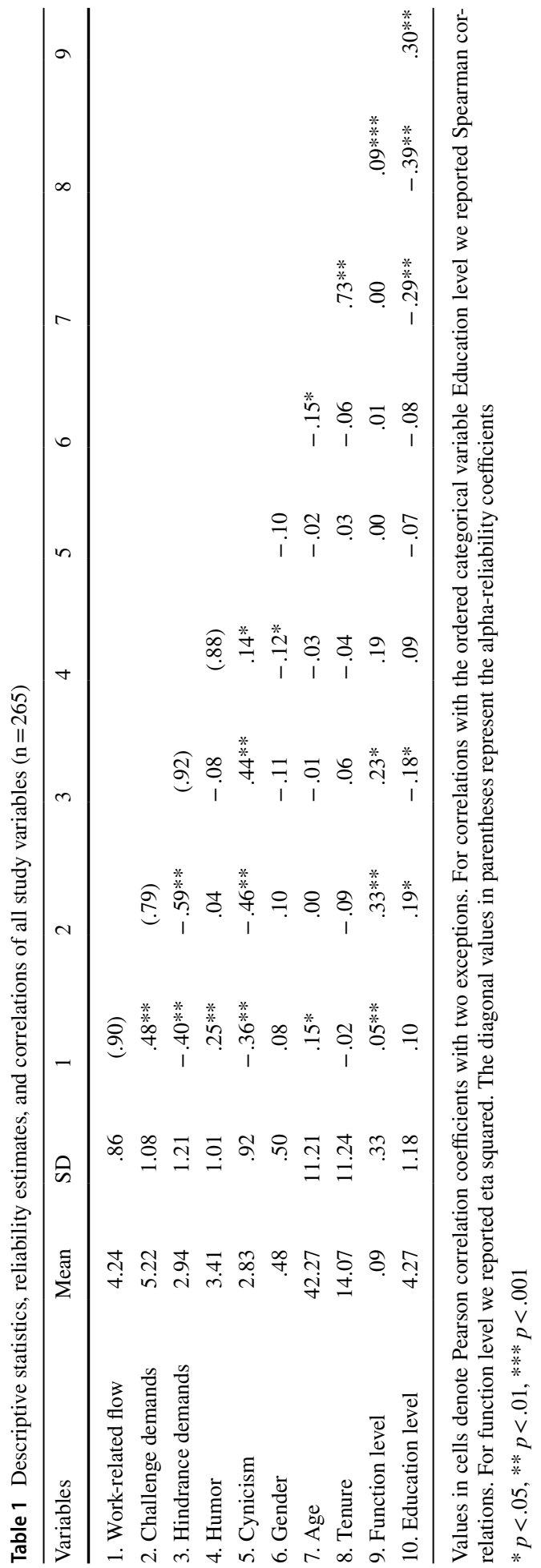




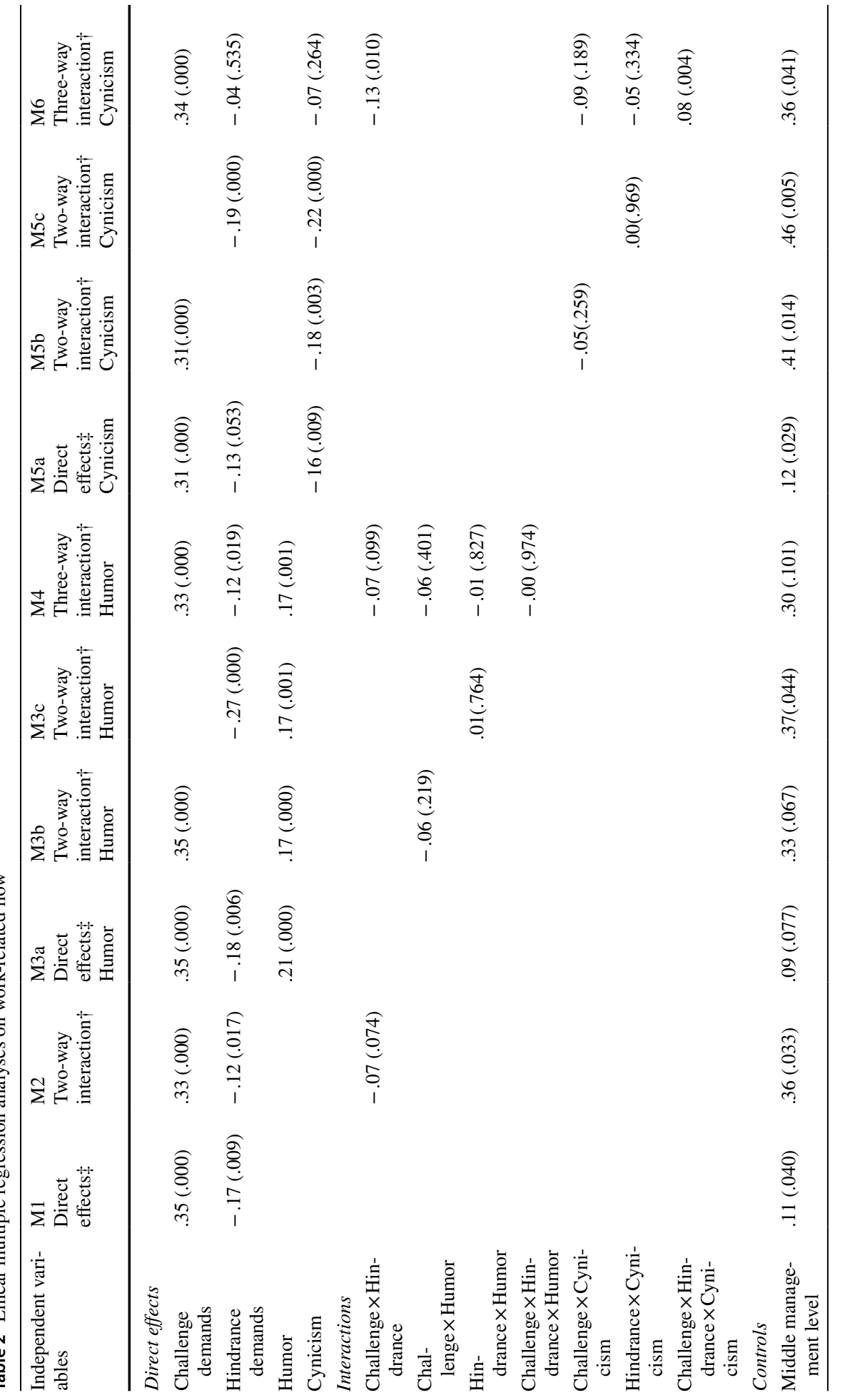




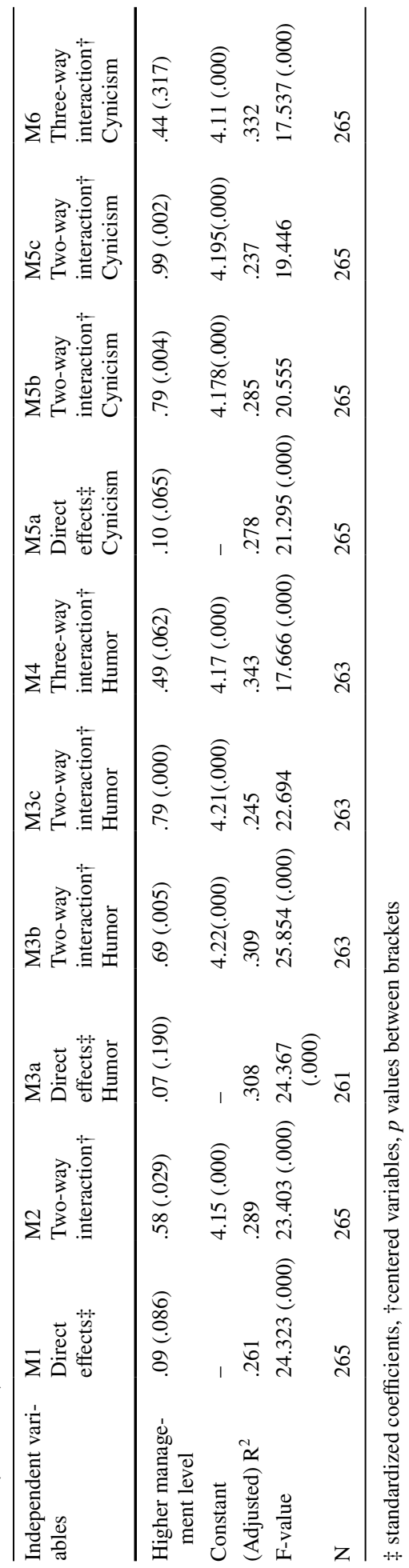




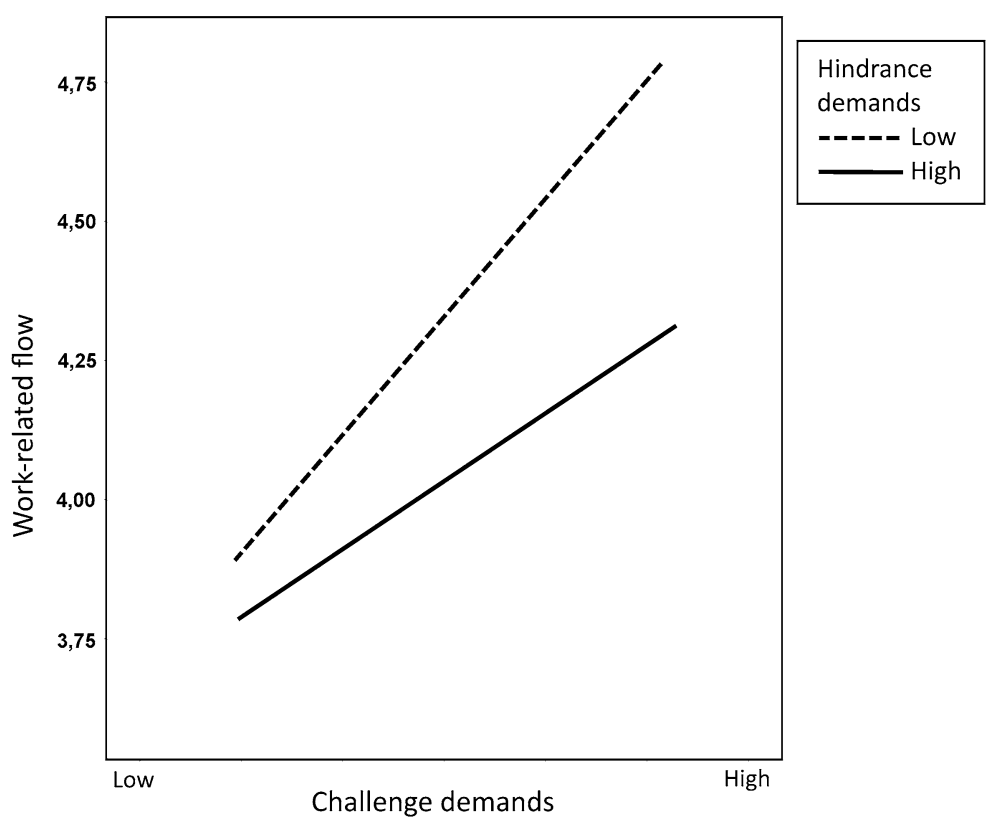

Fig. 2 Two-way interaction of hindrance demands and challenge demands with work-related flow

positively related to work-related flow $(\beta=.35, p=.000)$. Additionally, hindrance demands are negatively related to work-related flow $(\beta=-.17, p=.009)$. Hence, hypotheses 1 and 2 are supported. Model 2 (M2) includes the interaction between challenge and hindrance demands. The results show that the interaction is weakly significant and works in the expected way, namely hindrance demands negatively moderate the positive relationship between challenge demands and work-related flow. Following the procedure suggested by Aiken and West (1991), simple slope tests were conducted to statistically assess the interaction for both high (1 SD above the mean) and low (1 SD below the mean) levels of hindrance demands. Figure 2 shows that the positive relation between challenge demands and work-related flow is stronger when hindrance demands are low and weaker when hindrance demands are high. Thus, the positive relation between challenge demands and work-related flow is dampened - to some extent—by the presence of hindrance demands. This pattern of results supports Hypothesis 3.

Models M3a, b, c and M4 concern hypothesis 4. Hypothesis 4 suggests that the use of humor positively moderates the negative effect of hindrance demands on work-related flow. Whereas the inclusion of humor into the model increases the explained variance in work-related flow (M3a and M4), the three-way interaction is not supported by our data (M4). Note that we find support for the two-way interaction effect between challenge and hindrance demands when humor is included into the model, indicating the robustness of this relationship. M3b and M3c report on models in which only the two-way interactions (a) challenge $\times$ humor and (b) hindrance $\times$ humor are included. Both models, M3b and M3c, showed no significant two-way interaction effects. The three-way interaction model improves the explained variance from .245 (hindrance $\times$ humor) and .309 (challenge $\times$ humor) to .336 (challenge $\times$ hindrance $\times$ humor) . 


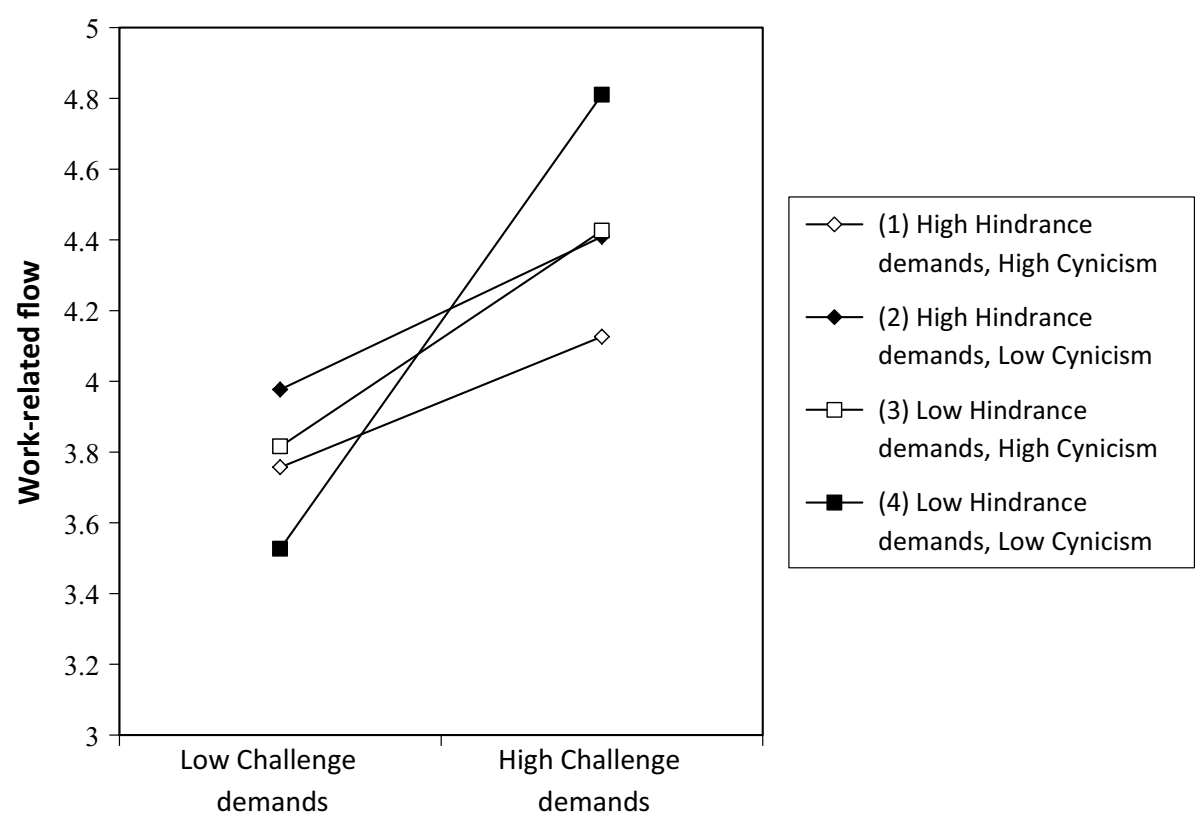

Fig. 3 Three-way interaction of hindrance demands, challenge demands, and cynicism with work-related flow

Models M5a and M6 include cynicism into the model specification. The results show that the use of cynicism positively moderates the negative effect of hindrance demands on the challenge-flow relationship. Once more, we also find support for the two-way interaction effect between challenge and hindrance demands in this model specification. M5b and M5c report on models in which only the two-way interactions (a) challenge $\times$ cynicism and (b) hindrance $\times$ cynicism are included. Both models, M5b and M5c, showed no significant two-way interaction effects. The three-way interaction model improves the explained variance from .237 (hindrance $\times$ cynicism) and .285 (challenge $\times$ cynicism) to .332 (challenge $\times$ hindrance $\times$ cynicism).

To assess the three-way interaction we use simple slope analysis. Figure 3 shows that the positive effect of challenge demands on flow is buffered when hindrance demands are high (line 4 vs. line 2). Slope difference tests (as recommended by Dawson and Richter 2006) revealed significant differences between the slopes of line 4 and line 2 $(p=.000)$. Adding cynicism to the interaction, slope difference tests revealed significant differences again between the slopes of line 4 and line $1(p=.001)$ and between the slopes of line 4 and line $3(p=.004)$. Hence, in line with Hypothesis 5 , high cynicism increases the buffering effect of hindrance demands on the challenge-flow relationship. 


\section{Conclusion and Discussion}

We investigated the associations of challenge and hindrance demands with work-related flow, and the potential effects of the use of humor and cynicism as stress-coping mechanisms. The results of our cross-sectional survey among 265 employees of a Dutch financial service organization provide support for the separate direct relationships between challenge stress demands and work-related flow (H1) and hindrance stress demands and work-related flow (H2). As expected, we found that challenge demands are positively associated with work-related flow (H1), whereas hindrance demands are negatively related to work-related flow $(\mathrm{H} 2)$. Therefore, these findings confirm the findings of previous studies that show that challenge demands and hindrance demands have an opposite effect on work outcomes (e.g. LePine et al. 2016; Cavanaugh et al. 2000).

We tested for interaction effects between challenge and hindrance demands and found weak support for our hypothesis that hindrance demands suppress the positive relationship between challenge demands and work-related flow (H3). This finding extends current knowledge about how the interaction of challenge and hindrance stress demands affect work outcomes, as hitherto studies have focused on the separate relationships of the two types of work stress demands on work outcomes (e.g. LePine et al. 2016).

Two three-way interactions were expected to qualify the main effects. We found support for a three-way interaction between challenge demands, hindrance demands, and cynicism in relation to flow experience (H5): The use of cynicism increases the weakening effect of hindrance demands on the challenge-flow relationship, generating lower levels of work-related flow than would be the case without the use of cynicism. These findings are in line with studies that show the predominantly adverse effects of the use of cynicism on performance and other work outcomes (Brandes and Das 2006; Byrne and Hochwater 2008; Chiaburu et al. 2013).

The hypothesized three-way interaction between challenge demands, hindrance demands, and humor (H4) was not supported by our data. Why did we not find a stresscoping effect of the use of humor in this study? Previous studies have shown that using humor may act as a stress buffer (e.g. Fritz et al. 2017; Kuiper and Martin 1993; Kuiper et al. 1995; Martin et al. 1993; Mesmer-Magnus et al. 2012). An explanation for the fact that our findings are not in line with these studies, may be found in the specific organizational context within which the data for this study were collected. During the time of the survey, rumors about an upcoming reorganization were spreading across the company. This may have caused feelings of uncertainty and worry among some of the employees. It is conceivable that, in this situation, the use of humor as coping mechanism was perceived as inappropriate. Previous research has shown that, in certain situations, such as when dramatic changes in the organization are at hand, leaders' use of humor may be counter-productive (Avolio et al. 1999). When the use of humor is considered as ill-chosen or as insufficient, it does not have the usual positive, moderating effects on work outcomes. A similar mechanism may be applicable in our study. It may be so that within the circumstances of the moment, employees did use humor, however, not as a coping mechanism to relieve the stress of hindrance demands. 


\subsection{Theoretical and Practical Implications}

The results of this paper have two kinds of implications for the theory on work-related flow. First, the results of this paper extend work-related flow theory by showing the impact of work demands on flow. In the literature, it is proposed that challenging work demands foster flow experience when adequate job resources are available (Bakker and van Woerkom 2017). Our study provides empirical grounding to the relationship between work demands and flow. In addition, it gives detailed insight into this relationship by distinguishing between challenge demands and hindrance demands and providing evidence for their differential associations with flow.

Second, this study adds to flow theory by introducing coping behavior as moderator for the relationship between work stress demands and flow. The use of humor and the use of cynicism have not been modeled in connection to work-related flow in previous flow studies. Specifically, we find support for adverse effects of the use of cynicism: our results show that cynicism is negatively correlated with flow (see Table 1) and that cynicism indirectly has an adverse effect on flow in interaction with work demands. This outcome enhances our knowledge of person-related factors that influence the likelihood of work-related flow.

Third, our study advances the challenge-hindrance stressors framework (see Cavanaugh et al. 2000), by demonstrating the interaction of challenge stress demands with hindrance stress demands. Moreover, our study explicitly connects stress demands to work-related flow. In this way, we add flow to the list of positive work outcomes known to be positively associated with work challenge demands.

At a practical level, this study suggests that managers should be alert to the use of cynicism among employees. Although some studies have suggested potential beneficial effects of cynicism on work outcomes such as performance, our study shows that the use of cynicism has adverse associations with work-related flow. Therefore, it is recommended that managers who wish to stimulate flow among their employees, pay attention to cynical behavior shown by employees and address the organizational issues that cultivate the negative attitude underlying the use of cynicism.

\subsection{Limitations and Avenues for Future Research}

Our study is subject to several limitations, of which we will discuss the main ones. First, in this study, flow was measured according to the WOLF inventory (Bakker 2008) using employees' self-reports about the past two weeks, which is quite common in the workrelated flow literature. However, this measurement method may not fully acknowledge the complex nature of the flow phenomenon that may involve both continuous and abrupt changes over time (Ceja and Navarro 2011). Research has indicated that, at the intra-individual level, different dimensions of the work-related flow experience as well as different levels of flow may be associated with different dynamic patterns, non-linear, random, or chaotic (Ceja and Navarro 2011, 2012; see also Bricteux et al. 2017). For example, whereas low levels of the challenge-skills balance were associated with a linear pattern, high levels of flow were associated with a non-linear, chaotic pattern. Given that the mean level of flow measured in our sample was not especially high, we assume that the method of data collection used and the linear regression techniques applied to analyze our data are justified. Further research using other research designs is needed to gain insight into the 
connections between work-related flow, work stressors and coping mechanisms over time, and to prove causal relationships among these variables.

Second, in our study, we did not distinguish between different types of cynicism. Conform the approach of Naus et al. (2007), we measured a combination of cognitive, affective and behavioral cynicism. Further research is needed to clarify to what extent the different dimensions of organizational cynicism are associated with increased hindrance demands effects and with reduced flow. Furthermore, we encourage additional research into different types of cynicism and humor in direct relation to work-related flow. It is worth adding that, although not part of the tested conceptual model, our data did show a direct, positive relationship between humor and flow. More research is needed that can tease out possible interactions between humor and cynicism in their relationship with work-related flow. In a similar vein, it would be interesting to explore other coping strategies, such as active coping or planning coping (Carver 1997), which could be used to cope with work stressors.

Third, despite the central role of the challenge-skill balance in flow theory, only the challenge part of this balance was studied here. This means that in our research design, we have disregarded the aspect of the extent to which skills match work challenges. Ideally, this aspect is taken into account when studying the relationship between challenge demands and work-related flow. Future studies into work demands and flow may integrate this aspect in their research designs.

Fourth, the role of employee motivation was not included in this study, and would be another interesting direction for future research into flow and work stressors. Previous studies have investigated how challenge and hindrance stress demands affect motivation (e.g. Webster et al. 2010). In order to better understand the mechanisms by which work stressors affect work-related flow, employee motivation and conditional variables influencing employee motivation, such as organizational culture, could be included in future research designs.

Despite these limitations and ideas for further investigations, we believe that our study has extended current understanding of the role of challenge and hindrance stress demands in relation to work-related flow, including the effects of coping mechanisms consisting of humor or cynicism.

Open Access This article is distributed under the terms of the Creative Commons Attribution 4.0 International License (http://creativecommons.org/licenses/by/4.0/), which permits unrestricted use, distribution, and reproduction in any medium, provided you give appropriate credit to the original author(s) and the source, provide a link to the Creative Commons license, and indicate if changes were made.

\section{References}

Aiken, L. S., \& West, S. G. (1991). Multiple regression: Testing and interpreting interactions. London: Newbury Park.

Aube, C., Brunelle, E., \& Rousseau, V. (2014). Flow experience and team performance: The role of team goal commitment and information exchange. Motivation and Emotion, 38, 120-130. https://doi. org/10.1007/s11031-013-9365-2.

Avolio, B. J., Howell, J. M., \& Sosik, J. J. (1999). A funny thing happened on the way to the bottom line: Humor as a moderator of leadership style effects. Academy of Management Journal, 42, 219-227. https://doi.org/10.5465/257094

Bakker, A. B. (2008). The work-related flow inventory: Construction and initial validation of the WOLF. Journal of Vocational Behavior, 72, 400-414. https://doi.org/10.1016/j.jvb.2007.11.007.

Bakker, A. B., \& van Woerkom, M. (2017). Flow at work: A self-determination perspective. Occupational Health Science, 1, 47-65. https://doi.org/10.1007/s41542-017-0003-3. 
Becker, T. E. (2005). Potential problems in the statistical control of variables in organizational research: A qualitative analysis with recommendations. Organizational Research Methods, 8, 274-289. https://doi. org/10.1177/1094428105278021.

Blaser, A. (1976). Irony and cynicism as defense mechanisms. Confinia Psychiatrica, 19, 80-88.

Boswell, W. R., Olson-Buchanan, J. B., \& LePine, M. A. (2004). Relations between stress and work outcomes: The role of felt challenge, job control, and psychological strain. Journal of Vocational Behavior, 64, 165-181. https://doi.org/10.1016/S0001-8791(03)00049-6.

Brandes, P., \& Das, D. (2006). Locating behavioral cynicism at work: Construct issues and performance implications. Research in Occupational Stress and Well Being, 5, 233-266. https://doi.org/10.1016/ S1479-3555(05)05007-9.

Breevaart, K., Bakker, A. B., Demerouti, E., \& Hetland, J. (2012). The measurement of state work engagement: A multilevel factor analytic study. European Journal of Psychological Assessment, 28, 305-312. https://doi.org/10.1027/1015-5759/a000111.

Bricteux, C., Navarro, J., Ceja, L., \& Fuerst, G. (2017). Interest as a moderator in the relationship between challenge/skills balance and flow at work: An analysis at within-individual level. Journal of Happiness Studies, 18, 861-880. https://doi.org/10.1007/s10902-016-9755-8.

Brislin, R. (1986). The wording and translation of research instruments. In W. Lonner \& J. Berry (Eds.), Field methods in cross-cultural research: Cross-cultural research and methodology series (pp. 137-164). Thousand Oaks: Sage Publications.

Byrne, Z. S., \& Hochwater, W. A. (2008). Perceived organizational support and performance: Relationships across levels of organizational cynicism. Journal of Managerial Psychology, 23, 54-72. https ://doi.org/10.1108/02683940810849666.

Carver, C. S. (1997). You want to measure coping but your protocol's too long: Consider the brief cope. International Journal of Behavioral Medicine, 4, 92-100. https://doi.org/10.1207/s15327558i jbm0401_6

Cavanaugh, M. A., Boswell, W. R., Roehling, M. V., \& Boudreau, J. W. (2000). An empirical examination of self-reported work stress among U.S. managers. The Journal of Applied Psychology, 85, 65-74. https://doi.org/10.1037//0021-9010.85.1.65.

Ceja, L., \& Navarro, J. (2011). Dynamic patterns of flow in the workplace: Characterizing within-individual variability using complexity science approach. Journal of Organizational Behaviour, 32, 627-651. https://doi.org/10.1002/job.747.

Ceja, L., \& Navarro, J. (2012). 'Suddenly I get into the zone': Examining discontinuities and nonlinear changes in flow experiences at work. Human Relations, 65, 1101-1127. https://doi. org/10.1177/0018726712447116.

Chang, S.-J., van Witteloostuijn, A., \& Eden, L. (2010). From the editors: Common method variance in international business research. Journal of International Business Studies, 41, 178-184. https://doi. org/10.1057/jibs.2009.88.

Chiaburu, D. S., Peng, A. C., Oh, I.-S., Banks, G. C., \& Lomeli, L. C. (2013). Antecedents and consequences of employee organizational cynicism: A meta-analysis. Journal of Vocational Behavior, 83, 181-197. https://doi.org/10.1016/j.jvb.2013.03.007.

Csikszentmihalyi, M. (1975). Beyond boredom and anxiety: Experiencing flow in work and play. San Francisco: Jossey-Bass.

Csikszentmihalyi, M. (1990). Flow: The psychology of optimal experience. New York: Harper \& Row.

Csikszentmihalyi, M., \& LeFevre, J. (1989). Optimal experience in work and leisure. Journal of Personality and Social Psychology, 56, 815-822.

Dawson, J. F., \& Richter, A. W. (2006). Probing three-way interactions in moderated multiple regression: Development and application of a slope difference test. Journal of Applied Psychology, 91, 917-926. https://doi.org/10.1037/0021-9010.91.4.917.

Demerouti, E. (2006). Job characteristics, flow, and performance: The moderating role of conscientiousness. Journal of Occupational Health Psychology, 11, 266-280. https://doi. org/10.1037/1076-8998.111.3.266.

Demerouti, E., Bakker, A. B., Sonnentag, S., \& Fullagar, C. J. (2012). Work-related flow and energy at work and at home: A study on the role of daily recovery. Journal of Organizational Behaviour, 33, 276-295. https://doi.org/10.1002/job.760.

Eisenberger, R., Jones, J. R., Stinglhamber, F., Shanock, L., \& Randall, A. T. (2005). Flow experiences at work: For high need achievers alone? Journal of Organizational Behavior, 26, 755-775. https:// doi.org/10.1002/job.337

Engeser, S., \& Rheinberg, F. (2008). Flow, performance and moderators of challenge-skill balance. Motivation and Emotion, 32(3), 158-172. https://doi.org/10.1007/s11031-008-9102-4. 
Engeser, S., \& Schiepe-Tiska, A. (2012). Historical lines and an overview of current research on flow. In S. Engeser (Ed.), Advances in flow research (pp. 1-28). New York: Springer. https://doi. org/10.1007/978-1-4614-2359-1.

Fagerlind, A.-C., Gustavsson, M., Johansson, G., \& Ekberg, K. (2013). Experience of work-related flow: Does high decision latitude enhance benefits gained from job resources? Journal of Vocational Behavior, 83, 161-170. https://doi.org/10.1016/j.jvb.2013.03.010.

Folkman, S., Lazarus, R. S., Dunkel-Schetter, C., DeLongis, A., \& Gruen, R. J. (1986). Dynamics of a stressful encounter: Cognitive appraisal, coping, and encounter outcomes. Journal of Personality and Social Psychology, 50, 992-1003. https://doi.org/10.1037/0022-3514.50.5.992.

Fong, C. J., Zaleski, D. J., \& Leach, J. K. (2014). The challenge-skill balance and antecedents of flow: A meta-analytic investigation. The Journal of Positive Psychology, 10, 425-446. https://doi. org/10.1080/17439760.2014.967799.

Fritz, H. L., Russek, L. N., \& Dillon, M. M. (2017). Humor use moderates the relation of stressful life events with psychological distress. Personality and Social Psychology Bulletin, 43, 845-859. https ://doi.org/10.1177/0146167217699583.

Fullagar, C. J., \& Kelloway, E. K. (2009). 'Flow' at work: An experience sampling approach. Journal of Occupational and Organizational Psychology, 82, 595-615. https://doi.org/10.1348/096317908X 357903.

Fullagar, C. J., Knight, P. A., \& Sovern, H. S. (2013). Challenge/skill balance, flow, and performance anxiety. Applied Psychology, 62, 236-259. https://doi.org/10.1111/j.1464-0597.2012.00494.x.

Henman, L. D. (2001). Humor as a coping mechanism: Lessons from POWs. International Journal of Humor Research, 14, 55-82. https://doi.org/10.1515/humr.14.1.83.

Hooper, D., Coughlan, J., \& Mullen, M. (2008). Structural equation modelling: Guidelines for determining model fit. Electronic Journal of Business Research Methods, 6, 53-60.

Hu, L. T., \& Bentler, P. M. (1999). Cutoff criteria for fit indexes in covariance structure analysis: Conventional criteria versus new alternatives. Structural Equation Modeling, 6, 1-55. https://doi. org/10.1080/10705519909540118.

Karfakis, N., \& Kokkinidis, G. (2011). Rethinking cynicism: Parrhesiastic practices in comtemporary workplaces. Culture and Organization, 17, 329-345. https://doi.org/10.1080/14759551.2011.59030 9.

Kim, T.-Y., Bateman, T. S., Gilbreath, B., \& Andersson, L. M. (2009). Top management credibility and employee cynicism: A comprehensive model. Human Relations, 62, 1435-1458. https://doi. org/10.1177/0018726709340822.

Kuiper, N. A. (2012). Humor and resiliency: Towards a process model of coping and growth. Europe's Journal of Psychology, 8, 475-491. https://doi.org/10.5964/ejop.v8i3.464.

Kuiper, N. A., \& Martin, N. A. (1993). Humor and self-concept. International Journal of Humor Research, 6, 251-270.

Kuiper, N. A., McKenzie, S. D., \& Belanger, K. A. (1995). Cognitive appraisals and individual differences in sense of humor: Motivational and affective implications. Personality and Individual Differences, 19, 359-372.

Kulas, J. T., Stachowski, A. A., \& Haynes, B. A. (2008). Middle response functioning in likert-responses to personality items. Journal of Business and Psychology 22:251-259. https://doi.org/10.1007/s1086 9-008-9064-2.

Lazarus, R. S., \& Folkman, S. (1984). Stress, appraisal, and coping. New York: Springer.

LePine, J. A., Podsakoff, N. P., \& LePine, M. A. (2005). A meta-analytic test of the challenge stressorhindrance stressor framework: An explanation for inconsistent relationships among stressors and performance. Academy of Management Journal, 48, 764-775. https://doi.org/10.5465/ amj.2005.18803921.

LePine, M. A., Zhang, Y., Crawford, E. R., \& Rich, B. L. (2016). Turning their pain to gain: Charismatic leader influence on follower stress appraisal and job performance. Academy of Management Journal, 59, 1036-1059. https://doi.org/10.5465/amj.2013.0778.

Lovelace, K. J., Manz, C. C., \& Alves, J. C. (2007). Work stress and leadership development: The role of self-leadership, shared leadership, psychical fitness and flow in managing demands and increased job control. Human Resource Management Review, 17, 374-387. https://doi.org/10.1016/j. hrmr.2007.08.001.

Mäkikangas, A., Bakker, A. B., Aunola, K., \& Demerouti, E. (2010). Job resources and flow at work: Modelling the relationship via latent growth curve and mixture model methodology. Journal of Occupational and Organizational Psychology, 83, 795-814. https://doi.org/10.1348/096317909X 476333. 
Martin, R. A., Kuiper, N. A., Olinger, L. J., \& Dance, K. A. (1993). Humor, coping with stress, selfconcept, and psychological well-being. International Journal of Humor Research, 6, 89-104.

Mesmer-Magnus, J., Glew, D. J., \& Viswesvaran, C. (2012). A meta-analysis of positive humor in the workplace. Journal of Managerial Psychology, 27, 155-190. https://doi.org/10.1108/02683941211199554.

Moneta, G. B., \& Csikszentmihalyi, M. (1996). The effect of perceived challenges and skills on the quality of subjective experience. Journal of Personality, 64, 275-310.

Nakamura, J., \& Csikszentmihalyi, M. (2002). The concept of flow. In C. R. Snyder \& S. J. Lopez (Eds.), Handbook of positive psychology (pp. 89-105). Oxford: University Press.

Naus, F., van Iterson, A., \& Roe, R. (2007). Organizational cynicism: Extending the exit, voice, loyalty, and neglect model of employees' responses to adverse conditions in the workplace. Human Relations, 60, 683-718. https://doi.org/10.1177/0018726707079198.

Ng, T. W. H.,\& Feldman, D. C. (2012). A comparison of self-ratings and non-self-report measures of employee creativity. Human Relations, 65, 1021-1047. https://doi.org/10.1177/0018726712446015.

Podsakoff, N. P., LePine, J. A., \& LePine, M. A. (2007). Differential challenge stressor-hindrance stressor relationships with job attitudes, turnover intentions, turnover, and withdrawal behavior: A metaanalysis. Journal of Applied Psychology, 92, 438-454. https://doi.org/10.1037/0021-9010.92.2.438.

Podsakoff, P. M., MacKenzie, S. B., Lee, J.-Y., \& Podsakoff, N. P. (2003). Common method biases in behavioral research: A critical review of the literature and recommended remedies. Journal of Applied Psychology, 88, 879-903. https://doi.org/10.1037/0021-9010.88.5.879.

Podsakoff, P. M., MacKenzie, S. B., \& Podsakoff, N. P. (2012). Sources of method bias in social science research and recommendations on how to control it. Annual Review of Psychology, 63, 539-569. https ://doi.org/10.1146/annurev-psych-120710-100452.

Reichers, A. E., Wanous, J. P., \& Austin, J. T. (1997). Understanding and managing cynicism about organizational change. Academy of Management Perspectives, 11, 48-59. https://doi.org/10.5465/ ame.1997.9707100659.

Rivkin, W., Diestel, S., \& Schmidt, K.-H. (2018). Which daily experiences can foster well-being at work? A diary study on the interplay between flow experiences, affective commitment, and self-control demands. Journal of Occupational Health Psychology, 23, 99-111. https://doi.org/10.1037/ocp00 00039.

Rodríguez-Sánchez, A. M., Schaufeli, W., Salanova, M., Cifre, E., \& Sonnenschein, M. (2011). Enjoyment and absorption: An electronic diary study on daily flow patterns. Work and Stress, 25, 75-92. https:// doi.org/10.1080/02678373.2011.565619.

Romero, E. J. (2005). The effect of humor on mental state and work effort. International Journal of Work Organisation and Emotion, 1, 137-149. https://doi.org/10.1504/IJWOE.2005.008818.

Romero, E. J., \& Cruthirds, K. W. (2006). The use of humor in the workplace. Academy of Management Perspectives, 20, 58-69. https://doi.org/10.5465/AMP.2006.20591005.

Salanova, M., Bakker, A. B., \& Llorens, S. (2006). Flow at work: Evidence for and upward spiral of personal and organizational resources. Journal of Happiness Studies, 7, 1-22. https://doi.org/10.1007/ s10902-005-8854-8.

Schaufeli, W. B., Salanova, M., González-Romá, V., \& Bakker, A. B. (2002). The measurement of burnout and engagement: A confirmatory factor analytic approach. Journal of Happiness Studies, 3, 71-92. https://doi.org/10.1023/A:1015630930326.

Sosik, J. J., Kahai, S. S., \& Avolio, B. J. (1999). Leadership style, anonymity, and creativity in group decision support systems: The mediating role of optimal flow. Journal of Creative Behavior, 33, 227-256.

Ventura, M., Salanova, M., \& Llorens, S. (2015). Professional self-efficacy as a predictor of burnout and engagement: The role of challenge and hindrance demands. Journal of Psychology, 149, 277-302. https://doi.org/10.1080/00223980.2013.876380.

Webster, J. R., Beehr, T. A., \& Christiansen, N. D. (2010). Toward a better understanding of the effects of hindrance and challenge stressors on work behavior. Journal of Vocational Behavior, 76, 68-77. https ://doi.org/10.1016/j.jvb.2009.06.012.

Widmer, P. S., Semmer, N. K., Kaelin, W., Jacobshagen, N., \& Meier, L. L. (2012). The ambivalence of challenge stressors: Time pressure associated with both negative and positive well-being. Journal of Vocational Behavior, 80, 422-433. https://doi.org/10.1016/j.jvb.2011.09.006.

Zubair, A., \& Kamal, A. (2015). Authentic leadership and creativity: Mediating role of work-related flow and psychological capital. Journal of Behavioural Sciences, 25, 150-171.

Publisher's Note Springer Nature remains neutral with regard to jurisdictional claims in published maps and institutional affiliations. 